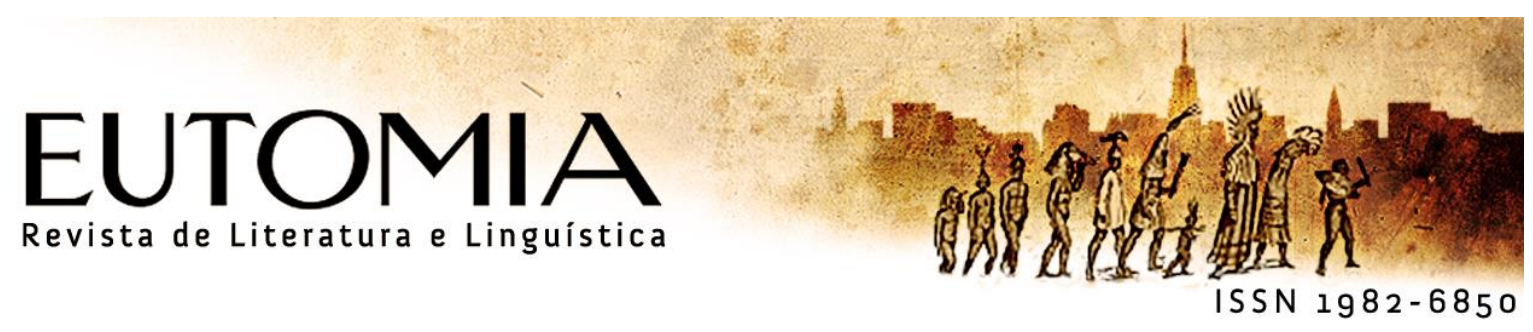

\title{
Valle-Inclán e a vanguarda no teatro espanhol
}

Darío Gómez Sánchezi (UFPE)

\begin{abstract}
Resumo: O surgimento das vanguardas teatrais está relacionado com a posta em questão do conceito de mimese e com a ênfase dada aos diversos códigos teatrais além do texto literário, processo que acontece de forma mais evidente nos países europeus com uma modernização mais consolidada nos finais do século XIX. No caso específico de Espanha, onde uma forte crise política e socioeconômica permeia as estruturas socioculturais, o drama burguês com suas variantes permanece como a forma dramática predominante ainda nos começos do século XX. Daí a importância da obra teatral de Ramón María del Valle-Inclán: sua proposta dos Esperpentos pode ser identificada como uma posta em questão do realismo dramát ico enquistado no teatro peninsular e, em consequência, o começo de sua renovação cênica e literária.
\end{abstract}

Palavras chave: Valle-Inclán, vanguarda, crise do drama, esperpento.

Abstract: The emergence of theatrical vanguards is related to the questioning of the concept of mimesis and the emphasis given to the various theatrical codes beyond the literary text, a process that is most evident in European countries with a more consolidated modernization in the late nineteenth century. In the specific case of Spain, where a strong socio-economic and political crisis permeates socio-cultural structures, bourgeois drama with its variants remains the predominant dramatic form still in the early twentieth century. Hence the importance of the theatrical work of Ramón María del Valle-Inclán: his proposal of the Esperpentos can be identified as a question of the dramatic realism embedded in the peninsular theater and, consequently, the beginning of its scenic and literary renewal.

Key words: Valle-Inclán, vanguard, crises of drama, esperpento

\section{Introdução}

O processo de gestação do teatro de vanguarda acontece entre finais do século XIX e começos do século XX e está relacionado com o questionamento do conceito de mimese ou representação predominante no teatro clássico e no drama 
burguês. A precisão do conflito, a progressão da intriga e a univoca concepção da personagem começam a serem postas em questão dentro de um universo relat ivizado onde se reconhece a possibilidade do conflito interno e inconsciente de um indivíduo atomizado. Tal processo tem, entre suas consequências mais notáveis, a perda da primazia do componente literário, reduzindo a importância do autor dramático, e a ênfase nas diversas linguagens teatrais diferentes da linguagem verbal, dando assim lugar à aparição do dramaturgo no sentido contemporâneo. Em síntese, trata-se da const ituição de um teatro não realista e predominantemente cênico ou performático.

Essa renovação teatral é realizada de forma mais evidente por autores provenientes de países com um processo de modernização mais consolidado nos finais do século XIX, como Henrik Ibsen (Noruega, 1828-1906), Auguste Strindberg (Suécia 1849 - 1912), Anton Tchekhov (Rússia 1860-1904) e Maurice Maeterlinck (Bélgica 1862- 1949), por exemplo. No caso específico da Espanha, a forte crise política e socioeconômica que acontece não é refletida pelo teatro da época, e o drama burguês com suas variantes permanece como a forma dramática predominante. Daí a importância da figura de Ramón María del Valle-Inclán (1866 1936), dado que suas peças são uma evidente tentativa de renovar o anquilosado panorama do teatro espanhol. Recuperando elementos do simbolismo, o modernismo e o expressionismo para relativizar a mimese realista, substituindo o psicologismo individual com a irregularidade de personagens absurdos, e misturando elementos narrativos, líricos e dramáticos com as diversas linguagens cênicas, o teatro de ValleInclán materializa na Espanha o processo de gestação da vanguarda. Mais concretamente, sua proposta dos Esperpentos pode ser ident ificada como uma posta em questão do realismo próprio do drama burguês enquistado no teatro peninsular e, em consequência, como o começo de sua renovação não só literária. Eis a síntese da reflexão que propomos nas seguintes páginas.

\section{Do drama burguês ao teatro de vanguarda}

Nos meados do século XVIII, principalmente na França, em consonância com a rejeição dos valores aristocráticos e a promoção da nova moral burguesa, acontece uma desafeição do público pelo teatro clássico e suas variantes que dá lugar à 
aparição do drama burguês: um gênero intermediário entre a grandiosidade da tragédia e a trivialidade da comédia e que promove valores como trabalho, sucesso, família, fazendo ênfase na caracterização individual de suas personagens (HAUSSER, 1994, cap. 3). Entre as diversas mudanças formais propiciadas por este novo gênero dramático se destaca a imposição da cena fechada - ou quarta parede -, que pretende encobrir ou suplantar com o ilusionismo realista a natureza fictícia da encenação, o que gera uma nova concepção da mimese teatral, muito mais radical na sua tentativa de representar a realidade.

A mágica da ilusão do teatro à italiana, relacionada com a dramaturgia préburguesa, tentava materializar na cena o universo da ficção (perspectiva, trompel'oeil, recursos técnicos), mas sem reproduzir a vida ou fazer crivel o universo da peça, pois sempre mantinha uma evidência da representação, seja pela máscara das personagens, pela declamação dos parlamentos ou pelo aparte em algumas réplicas. Diferente disso, o drama burguês quer apagar a evidência do teatral mediante uma pretendida ilusão de realidade, o que acaba tornando a cena artificial (TORO, 2008, ps. 30-62). Ao esquecer o caráter ficcional da encenação e obviar as contradições de uma mimese 'total', a mesma fica reduzida a falsa aparência.

Em "Discurso sobre a poesia dramática", de 1758, Denis Diderot (2005) esboça as características do que será o drama burguês - o genre sérieux, segundo ele o denomina -, fazendo ênfase na importância da pantomima dos atores e na descrição das cenas com o objetivo de propiciar a comoção e a verdade. Este último está relacionado com a emotividade e será explorado pelo melodrama romântico. A importância dada à atuação e à caracterização das cenas são antecedentes definitivos do realismo desenvolvido por Emile Zolá (1979) em "O naturalismo no teatro", de 1881, no qual propõe a observação psicológica e social do romance realista como base da criação teatral: "o teatro será naturalista ou não será". Além de favorecer o surgimento da figura do diretor de cena, a proposta de Zolá consolida a mimese realista e a promoção do ilusionismo teatral.

Assim, nos finais do século XIX, ○ teatro oscila entre as encenações (hiper)realistas de autores naturalistas e as explorações dramáticas de autores que, ainda dentro do realismo, antecipam no teatro a crise da representação. No primeiro caso o teatro evolui para um espetáculo literário ou musical, de caráter recreativo e 
comercial (como acontece na Espanha até a segunda década do século seguinte), na segunda linha se gestam os movimentos de vanguarda que provocarão a renovação definit iva da cena teatral.

O processo que leva do teatro realista às vanguardas é conhecido como a crise do drama absoluto. Segundo Peter Szondi (2001), entre 1880 e 1925 há um questionamento da tradição dramática europeia e do realismo teatral: na sua função imitativa, na linguagem do diálogo, na condição da personagem e na natureza da representação. O drama burguês definido por Diderot e o drama naturalista caracterizado por Zolá enfrentam a crise da ilusão da representação em peças aparentemente realistas como "Espectros" (1881) de Henrik Ibsen, "Senhorita Júlia" (1888) de August Strindberg e "As três irmãs" (1900) de Anton Tchekhov; peças e autores que sentam as bases para a posterior ruptura simbolista com a representação realista.

De fato, o simbolismo, característico de peças como "A Intrusa" (189o) de Maurice Maeterlinck e "O Marinheiro" (1913) de Fernando Pessoa, pode ser considerado como a ponte entre o drama burguês e as vanguardas teatrais; se bem alguns estudiosos estabelecem a origem dessa transição em "Ubu Rei" (1896), de Alfred Jarry e sua consolidação em "Seis personagens na procura de autor" (1921), de Luigi Pirandello. Na obra de Jarry apresenta-se um retrato antecipado das consequências sangrentas dos abusos da burguesia com uma linguagem e uma estrutura formal revolucionárias, evidentes desde a primeira fala da cena: "Merde!". E a obra de Pirandello, com seu argumento totalmente inaugural e cujo processo de gestação está detalhado num texto do próprio autor sobre a criação artística, consolida múltiplas transformações cênicas, entre elas a dês-psicologização e relativização da personagem, a trivialização do conflito dramático e o rompimento definitivo da quarta parede.

Durante esse complexo processo da crise do drama acontecendo em outros contextos, na Espanha, no entanto, se perpetua a tendência realista com algumas fugas esporádicas para um teatro poético com lampejos simbolistas, mas com uma notável ausência de obras e autores que colocassem em questão o padrão do drama naturalista, pelo que o surgimento da vanguarda não se consolida, pelo menos até a aparição de algumas peças de Ramón del Valle-Inclán, que evidencia na sua produção 
teatral grande parte do processo de transição entre o realismo do drama burguês e a experimentação das vanguardas cênicas.

\section{O teatro espanhol na transição ao século $X X$}

Enquanto outras nações desenvolvem um teatro que evidencia a crise da representação como consequência da crise da modernidade, na Espanha dos finais do século XIX e começos do século XX, as filas se fecham para evitar qualquer renovação nesse campo. Isto porque um grande setor da burguesia local considera que a função do teatro deve ser ampliar a distância entre a ilusão do cenário e a complexa realidade nacional (MONLEÓN, 1999, p. 21). No período compreendido entre 1880 e 1920, se bem se apresentam diversas manifestações de criação teatral, as mesmas não conseguem materializar uma renovação do fato cênico nacional, como acontece em outras latitudes. E ainda que no período posterior a 1898 a situação de crise em diversos âmbitos da vida política e cultural propicia a busca de novos horizontes estéticos, mais críticos e modernos, no teatro as diversas tentativas de impor as novas propostas não passam de intenções isoladas, e a tendência realista cont inua a se impor sobre os experimentos particulares de modernização e até sobre outras formas nacionais mais inovadoras como o sainete e/ou o teatro costumbrista. Na história da arte espanhola é um fato assumido a crise do teatro nas primeiras décadas do século passado, mas uma crise não no sentido projetivo de busca de novas linguagens, como a que leva à gestação das vanguardas em outros países, mas no sentido conservador, produto da repetição de fórmulas conhecidas e da rejeição das novas possibilidades cênicas e dramatúrgicas. E essa crise teatral é tanto estética como social, pois neste caso específico não é fácil separar as categorias porque o teatro está no centro das coisas que afetam a vida coletiva (DOUGHERTY, 1984, p. 155)

No entanto, é possível diferenciar algumas causas internas e externas do anacronismo teatral. Entre estas últ imas se ident ificam a falta de uma crítica teatral fundamentada e moderna e o alto regime de imposto e gravames às companhias e empresários teatrais, o que faz com que eles prefiram não correr riscos e programar espetáculos previsíveis com um teatro realista de fórmulas conhecidas e um evidente 
apelo comercial (REBOLLO, 2004, p.64). E entre as causas internas estaria certa insuficiência do teatro espanhol dos começos do século XX para expressar a alma moderna, o que acaba facilitando o estancamento no naturalismo finissecular, e a pouca incidência das novas teorias teatrais europeias no reduzido quadro de autores da época (depois de José Echegaray com seus melodramas e Benito Pérez Galdós, mais reconhecido como romancista, só se destacam, entre outros poucos, os irmãos Alvarez Quintero com suas peças costumbristas, Pedro Muñoz Seca e Carlos Barrera como comediógrafos e Jacinto Benavente, cujas obras oscilam entre a adaptação e a renovação e quem será o antagonista teatral de Valle-Inclán), assim como a falta de formação de atores (pelo predomínio do estrelismo) e, especialmente, de diretores de cena: figura fundamental no processo de modernização das linguagens teatrais. Assim sendo, o negócio e o divertimento acabam se impondo sobre as escassas pretensões artísticas, provocando um receio diante das novidades cênicas, as quais são obstaculizadas já em seu surgimento (RUBIO, 1998, s.p.), como testemunha a escassa encenação das obras de Valle-Inclán.

Entre as características comuns que permitem o surgimento do teatro de vanguarda em vários países da Europa nos finais do século XIX, mas na Espanha só depois dos anos vinte do século $X X$, temos a consolidação do teatro artístico realizado pelos denominados "Teatros da arte" ou teatros de câmara, que durante muito tempo representam a única alternat iva ao teatro comercial; o afastamento do teatro literário e verossímil e a aproximação à representação como ritual ou acontecimento, favorecendo a participação do público; a simplificação dos elementos da encenação, na linha de um teatro simbolista (e do qual o antecedente espanhol mais notável é Fedra de Miguel de Unamuno); a recuperação de formas populares de representação (o teatro de rua), a consolidação das figuras do diretor de cena e do crítico, e a renovação das formas de expressão (OLIVA, 2002, p. 115). E são estas as características que encontraremos presentes de uma ou outra forma na produção dramática de Valle-Inclán, quem, questionando o realismo imperante derivado do mercantilismo teatral, consegue colocar o teatro espanhol no panorama do teatro europeu de vanguarda com uma dramaturgia inovadora, artística, e que gera diversos desafios tanto para sua encenação quanto para sua recepção. 


\section{O teatro de Valle-Inclán}

Aproximadamente umas vinte peças integram o catálogo teatral de Ramón Valle-Inclán, e entre elas é possível achar obras de perfis muito distintos, desde o drama burguês e o teatro poético até a farsa grotesca e o diálogo expressionista, passando pela tragédia sent imental e a peça simbolista. Poderíamos afirmar que, em pequena escala, a obra de Don Ramón resume e sintetiza as tendências teatrais que Ihe foram contemporâneas. E especialmente é imperativo concluir que com ele o teatro espanhol entra a fazer parte, tardia e definitivamente, do panorama das vanguardas europeias.

Duas características confirmam a renovação vanguardista levada a cabo pelo autor galego no panorama do teatro espanhol: o questionamento da noção de mimese própria do drama burguês e a concepção do teatro como totalidade cênica. No primeiro caso, aos espelhos complacentes do teatro realista, o autor basco opõe as deformações sistemáticas que culminarão na concepção de seus esperpentos, e no segundo ponto há uma superação da concepção do drama como sendo exclusivamente uma criação literária para vincular a linguagem cênica na sua dimensão performática.

Além de ser um escritor de diversos gêneros, Valle-Inclán mostra ao longo de sua vida uma atração pelo mundo do teatro. Só o fato de ele ser, além de autor, ator, cenógrafo e diretor de cena, confirma sua modernidade teatral, dado que no teatro burguês, realista e/ou comercial que predomina na Espanha até sua época, o autor dramático poucas vezes faz parte do mundo do teatro, e é basicamente um criador literário. Isto porque no teatro espanhol prevalece uma compreensão da dramaturgia segundo a concepção neoclássica francesa, segundo a qual uma peça teatral é dominada pela intriga, pela retórica e pelo tratamento psicológico das personagens criadas pelo autor; ideia que vai à contramão de uma nova concepção da dramaturgia, de origem germânica e anglo-saxônica, relacionada com a encenação realizada pelo diretor de cena levando em conta a diversidade de linguagens teatrais. Valle-Inclán é um dramaturgo no sentido mais moderno do termo, ou seja, aquele que escreve tendo presente a diversidade dos códigos cênicos e não só a linguagem verbal. 
"A grande obra teatral requer de um cenário" insistia, manifestando assim sua visão performática do teatro. E uma evidência incontestável da importância desse traço vanguardista são suas didascálias, as quais, não poucas vezes e com uma notável estilização verbal, especificam de maneira bastante singular as características de sua encenação - motivado seguramente pela dúvida de que fosse corretamente executada. A linguagem popular (mistura de arcaísmos e jargão madrilenho com galleguismos e americanismos), a combinação do gênero dramático com elementos líricos e narrat ivos (antecipando propriedades do teatro épico brechtiano), a definição visual de atmosferas e sensações a part ir de objetos e espaços (e não só a criação de decorados ou da caracterização de personagens) são algumas das singulares características destas didascálias. De fato, essa singularidade fez com que muitas vezes elas fossem consideradas como teatralmente inúteis, prolixas, ou excessivamente literárias. Mas, como tem sido identificado, no seu estatismo pictórico e na ambivalência entre o teatral e o literário, as didascálias de Valle-Inclán devem ser lidas como "água-fortes narrativas os quadros de costumes que contribuem à plasticidade de seu teatro" (SÀNCHEZ, 1998, 311). E poderíamos agregar que, na sua singularidade, vão além da linguagem própria do realismo dramático para vincular a totalidade dos códigos teatrais.

Essa visão totalizante com características absolutamente audazes e inovadoras -além do interesse comercial dos donos dos teatros- faz com que Don Ramón enfrente dificuldades para a estreia da maior parte de suas obras. Alguns críticos de sua época se referem a suas peças como sendo "boa literatura e mau teatro", seguindo o costume de julgar a obra teatral segundo os padrões do drama burguês, e também por conta das dificuldades de recepção por parte de um público acostumado às formas tradicionais do realismo dramático, os quais Valle-Inclán pretende colocar em questão (BUERO, 1994). O fato é que na sua linguagem teatral, cheia de dinamismo e musicalidade, Valle incorpora a diversidade da linguagem cênica, que, além do gesto e da palavra, está conformada pela atuação, a iluminação, a cenografia, etc., todo aquilo que a dramaturgia no sentido moderno privilegia sob o conceito de teatro total ou encenação, e pelo qual apresenta dificuldades particulares e demanda altos custos de realização. 
Mas, além da dimensão performática evidente nas suas didascálias, o teatro de Valle-Inclán é vanguardista, principalmente, pela sua posta em questão da mimese realista. E esse questionamento do realismo não é exclusivo da fase final de sua criação dramática, com a criação de seus esperpentos; ele tem seus antecedentes na produção inicial, com diferentes manifestações da deformação e do grotesco, as quais antecipam o caráter renovador de sua obra, ainda nas suas peças mais tradicionais.

É frequente entre os críticos dividir em duas fases a produção dramática de Valle-Inclán: a fase modernista ou galega e a fase esperpéntica ou madrilenha. Esta última começaria depois de uma extensa interrupção na sua produção criativa, acontecida entre 1913 e 1920, da qual o escritor retorna com uma evidente mudança manifesta em sua obra Luces de bohemia (1920), e na que aparece uma primeira definição do esperpento. Se incluem também nesse segundo momento seu Tablado de marionetas para educación de príncipes (1920/1926): compilação de farsas nas quais o grotesco ocupa um lugar destacado, Los cuernos de Don Friolera (1921), Las galas del difundo (1926) e La hija del capitán (1927), as três reunidas em 1930 sob o título de Martes de Carnaval, e nas quais concretiza sua proposta sobre o esperpento e a deformação na arte; e Retablo de la Avaricia, la Lujuria y la Muerte (1927), que reúne suas últ imas peças: Ligazón, La rosa de papel, La cabeza del Bautista e Sacrilegio, além de El embrujado, peça de origem anterior.

A fase inicial do autor galego, na transição do século, obedece à proposta pósromânt ica do drama burguês e/ou da tragédia doméstica em peças como El yermo de las almas (1899/1915) e Jardin novelesco (1905/1908), nas quais o tema da morte é central, deixando evidente a influência do simbolismo. Depois da adaptação parcial para teatro de seu romance Sonata de Otoño, com o título de El marqués de Bradomin (1906), começa a série de Comédias bárbaras (1908). Lugar de destaque merece o conjunto de suas farsas: a peça infant il Farsa infantil de la cabeza del dragón (estreada em 1910 e publicada em 1914), a primeira versão de La farsa y licencia de la reina castiza e La marquesa Rosalinda, farsa sentimental y grotesca, inspirada na comédia da arte (estreada em 1912 e publicada no ano seguinte), - as quais aparecem reunidas com Farsa de la Enamorada del Rey(1920) e Farsa y Licencia de la Reina Castiza (1920/1922, estreada en 1931) em Tablado de marionetas para educación de príncipes(1926) -. Fecha esta primeira fase El embrujado (1912), tragédia 
shakespeariana em ambiente rural galego, e depois da qual começara a referida interrupção criativa de sete anos na sua produção teatral.

É indiscutível que o caráter vanguardista do autor galego só se concretiza na segunda fase, mas, como foi antecipado, o quest ionamento do realismo teatral já está presente na sua produção inicial. Um exemplo específico desse não realismo é a presença de cadáveres que, em várias peças, estão presentes de formas diversas no mundo dos vivos. E de maneira mais geral, pode se falar da deformação e/ou do grotesco como caracteristicas constante de seu teatro (OLIVA, 2002). Neste ponto é importante anotar que, na fase inicial, a deformação aparece acompanhada de elementos mágicos e misteriosos da tradição popular galaica, evidenciando traços poéticos de origem simbolista que permanecerão nas farsas e nos esperpentos da segunda fase de sua produção teatral, ainda que com uma visão sócio histórica mais comprometida e com uma função crítica da realidade espanhola, como acontece em Luzes de Boemia.

O simbolismo, é bom lembrar, propõe uma transformação ou metamorfose das personagens, um uso poético da linguagem e a fusão contrastada das diversas linguagens cênicas: música, pintura, dança, com a finalidade de obter uma atmosfera onírica, cultuar a imaginação, a magia e a fantasia, e não a realidade. É por isso que pode ser considerado como a ponte entre as formas teatrais aparentemente realistas e as elaborações cênicas vanguardistas. Nesse sentido, a obra de Valle-Inclán, nas suas duas fases, sintet iza o processo de gestação das vanguardas que se deu nos finais do século XIX em outras lat itudes.

Mas o fato que nos interesa destacar é que a deformação e o grotesco é uma constante que se va intensificando paulat inamente na obra deste autor. No começo, nas Comedias bárbaras, conservando o alento romântico, o grotesco aparece como uma leve perturbação dentro de um universo idealizado. Posterioremente alcança maior presença, sendo um componente fundamental de suas farsas, especialmente de La Marquesa Rosalinda..., na qual aparecem personagens galantes, como a protagonista, do lado de pícaros rufiais, como os contratados para combater o Arlequim, numa equilibrada harmonia entre o sublime e o grotesco, harmonia que será desfeita pelos esperpentos, nos quais acaba triunfando o lado grotesco, como acontece em Luces de bohemia (SHCIAVO, 1999). E essa evolução progressiva do 
grotesco nos faz pensar que não é tão definit iva a divisão entre duas fases dramáticas propostas, pelo que é mais conveniente falar de uma progressão que vai das deformações iniciais ao equilíbrio com o sublime até chegar a imposição definit iva do grotesco. Além disso, é possível pensar que a alternância entre o grotesco e o sublime presente nas suas farsas, e que é alterado na fase esperpêntica, aparece não só nas situações e personagens, mas também no uso da linguagem, vinculando o lirismo pósromânt ico próprio de um universo idealizado e a experimentação expressiva a part ir da linguagem popular.

O fato é que Valle-Inclán opõe as deformações e o grotesco ao teatro convencional e agônico que predomina na Espanha de começos do século $\mathrm{XX}$, isto porque, como ele mesmo afirma, "o sentido trágico da vida espanhola só pode se dar com uma estét ica sistemat icamente deformada" denominada esperpento.

\section{O esperpento}

Não sem algumas discussões, a consideração de 'esperpento' se aplica especificamente a quatro peças de Valle-Inclán: Luces de bohemia, La hija del capitán, Las galas del difunto e Los cuernos de Don Friolera, ainda que, como foi mencionado, possa estar latente em quase todas suas obras como elaboração da deformação e do grotesco. Com relação à conceitualização do próprio autor, são identificadas três fontes da teoria do esperpento: a cena XII de Luces de Bohemia, o prólogo e o epílogo de Los cuernos de don Friolera e as declarações sobre as três formas de ver o mundo concedidas em 1928.

Na cena XII de Luces de Bohemia (1920), o escritor protagonista Max Estrella expõe a Don Latino seu programa artístico, fazendo menção por vez primeira do termo 'esperpento'. Eis o contexto:

MAX: La tragedia nuestra no es tragedia.

DON LATINO: ¡Pues algo será!

MAX: El Esperpento.

E mais para frente:

MAX: Los héroes clásicos reflejados en los espejos cóncavos dan el Esperpento. El sentido trágico de la vida española sólo puede darse con una estét ica sistemáticamente deformada.

DON LATINO: ¡Miau! ¡Te estás contagiando!

MAX: España es una deformación grotesca de la civilización europea. 
DON LATINO: ¡Pudiera! Yo me inhibo.

MAX: Las imágenes más bellas en un espejo cóncavo son absurdas.

DON LATINO: Conforme. Pero a mí me divierte mirarme en los espejos de la calle del Gato.

MAX: Y a mí. La deformación deja de serlo cuando está sujeta a una matemática perfecta, Mi estética actual es transformar con matemática de espejo cóncavo las normas clásicas

(VALLE-INCLÁN, 2007, p. 139)

A metáfora do espelho é bastante significativa se pensarmos que refletir a realidade é a intenção do teatro mimético. Mas, neste caso, são espelhos côncavos, ou seja, deformantes, os únicos que podem dar conta da grotesca realidade espanhola da época. Nesse sentido, aos espelhos cúmplices, feitos para retocar e adoçar a realidade, Valle opõe às imagens deformadas como única possibilidade de expressar o complexo momento histórico da Espanha (MONLEÓN, 1999, p. 21)

Los cuernos de Don Friolera (1930) foi publicada por entregas entre os meses de abril e agosto de 1921. Além do texto central, está constituída por um epílogo e um prólogo nos quais o autor apresenta dois personagens que atuam como porta-vozes de sua ideologia estét ica. Especificamente, algumas declarações de Don Estrafalario, tendo por testemunha Manolito, tais como a "superação da dor e do riso", "conversações dos mortos ao se contar histórias dos vivos" ou "ver o mundo com a perspectiva da outra ribeira" podem ser relacionadas com as ideias sobre o esperpento expressadas por Valle em outros contextos - como numa entrevista de 1921 onde manifesta: "esta modalidade consiste em buscar o lado cômico no trágico da vida".

Mas será a entrevista concedida a Gregório Martínez Sierra e publicada no jornal espanhol $A B C$ o dia 7 de dezembro de 1928, titulada "Hablando con ValleInclán", onde se encontra a mais importante elaboração teórica do autor do que anteriormente tinha sido expressado pelos seus personagens:

Comenzaré por decirle a usted que creo que hay tres modos de ver el mundo, artística o estét icamente: de rodillas, en pie o levantado en el aire.

Cuando se mira de rodillas -y ésta es la posición más antigua en la literatura- se da a los personajes, a los héroes, una condición superior a la condición humana, cuando menos a la condición del narrador 0 del poeta. Así Homero atribuyó a sus héroes condiciones que en modo alguno tienen los hombres. Se crean, por decirlo así, seres superiores a la naturaleza humana: dioses, semidioses y héroes. 
Hay una segunda manera, que es mirar a los protagonistas novelescos como de nuestra propia naturaleza, como si fuesen nuestros hermanos, como si fuesen ellos nosotros mismos, como si fuera el personaje un desdoblamiento de nuestro 'yo", con nuestras mismas virtudes y nuestros mismos defectos. Esta es, indudablemente, la manera que más prospera [...] Los personajes, en este caso, son de la misma naturaleza humana, ni más ni menos, que el que los crea: son una realidad, la máxima verdad.

$Y$ hay otra tercera manera, que es mirar el mundo desde un plano superior, y considerar a los personajes de la trama como seres inferiores al autor, con un punto de ironía. Los dioses se convierten en personajes de sainete. Esta es una manera muy española, manera de demiurgo, que no se cree en modo alguno hecho del mismo barro que sus muñecos [...].

(VALLE-Inclán apud IRIARTE, 1998, p. 29-30)

Há nesta e nas diferentes elaborações do autor galego sobre o esperpento a intenção de configurar uma nova proposta teatral, baseada numa visão do mundo e da arte bem particular, e de um evidente caráter vanguardista. Contudo, tais elaborações estão longe de constituir um conjunto teórico sistemático de definições concluídas. Isto por vários motivos. Em primeiro lugar, Valle-Inclán é basicamente um poeta, pelo que muitas de suas propostas sobre o assunto estão expressas em termos metafóricos e não em conceitos. Além disso, e precisamente pelo seu caráter vanguardista, os esperpentos são primordialmente uma proposta de criação e encenação, pelo que desbordam a possibilidade de um delineamento teórico definitivo. A concepção do esperpento vai além de teorias e definições, e das mesmas expectativas de seu autor, para vincular sua realização cênica, sua dimensão performática, nem sempre possível de ser estabelecida.

Mas, ainda com estas limitações, é possível identificar nas elaborações teóricas de Valle-Inclán os elementos fundamentais que caracterizam o esperpento como uma proposta teatral de vanguarda: a visão deformada ou grotesca da realidade como desconstrução da mimese realista e a preocupação pelos efeitos teatrais manifesta na peculiaridade de suas didascálias. A estes dois aspectos é necessário agregar a linguagem castiça, como característica bem singular deste autor, a qual o diferencia não só de seus contemporâneos espanhóis, mas também de outros autores europeus de começos de século. De fato, a singularidade no uso da língua espanhola é um dos caracteres mais definitivos do esperpento, e reclamaria um desenvolvimento específico. O gênero dramát ico para Valle-Inclán supõe não só uma 
deformação da realidade e uma ênfase na encenação, mas também uma forma singular de enunciação.

Estranha mistura de sainete e paródia, de teatro grotesco e peça do absurdo, os esperpentos encenam os contrastes e a distorção de uma sociedade em crise, a impassibilidade de sent imentos diante da desgraça, além de levar a cabo uma mistura de registros linguísticos e uma ruptura com as convenções e academicismos. Tudo isto como uma nova forma de olhar o mundo, como uma proposta para expressar o universo cultural vivenciado pelo autor. O esperpento não é só um gênero teatral, nem uma linguagem singular, é, sobretudo, a expressão de uma atitude, de uma visão da história de Espanha, e, especialmente, a ressurreição estética e social de uma das tradições cênicas mais importantes de ocidente: o teatro espanhol.

\section{Referências Bibliográficas}

BUERO VALLEJO, Antonio. Valle Inclán. In: Obra completa. Tomo II. Madrid: Espasa Calpe, 1994, p. 1148-1156. Disponível em: http://www.cervantesvirtual.com/obra/valleinclan--o/ Acesso em: 6 dez. 2018.

DIDEROT, Denis. Discurso sobre a poesia dramática. Tradução de Franklin de Mattos. São Paulo: Cosac Naify, 2005.

DOUGHERTY, D. Talla convulsa: La crisis teatral de los años 20. Murcia: Universidad de Murcia, 1984 .

HAUSSER, Arnold. Historia social del arte y la literatura. Tomo 2. Barcelona: Labor, 1994.

IRIARTE, Amalia. Tragedia de fantoches. Bogotá: Plaza \& Janés, 1998.

MONLEÓN, José. Una ruptura fecunda en el teatro español del siglo XX. In: CUEVAS, Cristóbal; BAENA PEÑA, Enrique (Org.) Valle-Inclán universal: la otra teatralidad. Málaga: Universidad de Málaga, Publicaciones del Congreso de Literatura española contemporânea, 1999, p. 17-45.

OLIVA, César: El simbolismo en el teatro de Valle Inclán. Anales de Literatura Española. Universidad de Alicante, n. 15, p. 109-122, 2002. Disponível em: http://www.cervantesvirtual.com/obra/n-15-2002/ Acesso em: 6 dez. 2018.

REBOLLO, Mar: La crisis teatral de los años veinte en España. Revista de Estudios culturales, v. 20, p. 55-68, 2004. Disponível em: https://digitalcommons.conncoll.edu/cgi/viewcontent.cgi?referer=https://www.google.com .br/\&httpsredir=1\&article=1197\&context=teatro Acesso em: 6 dez 2018. 
RUBIO, Jesús (Org.) La renovación teatral española de 1900: Manifiestos y otros ensayos. Madrid: Publicaciones de la Asociación de Directores de Escena de España, 1998. Disponível em: http://parnaseo.uv.es/Ars/ESTICOMITIA/Numeroo/indicecero/az.htm Acesso em: 6 dez. 2018

TORO, F. Semiótica del teatro: del texto a la puesta en escena. Buenos Aires: Galeerna, 2008.

SÁNCHEZ, Jordi. A propósito de las acotaciones de Valle Inclán. In: CUEVAS, Cristóbal; BAENA PEÑA, Enrique (Org.) Valle-Inclán universal: la otra teatralidad. Málaga: Universidad de Málaga, Publicaciones del Congreso de Literatura española contemporánea, 1999, p. 303-322.

SHCIAVO, Leda. El camino del grotesco en Valle-Inclán. In: CUEVAS, Cristóbal; BAENA PEÑA, Enrique (Org.) Valle-Inclán universal: la otra teatralidad. Málaga: Universidad de Málaga, Publicaciones del Congreso de Literatura española contemporánea, 1999, p. 74-92.

SZONDI, Peter. Teoria do drama moderno [1880-1950]. São Paulo: Cosac \& Naify, 2001

VALLE-INCLÁN, Ramón del. Luces de bohemia. Edición e introducción de Alonso Zamora Vicente; guía de lectura y glosario de Joaquín del Valle-Inclán. Madrid: Espasa Calpe, 2007.

. Martes de carnaval. Opera Omnia, XVII. Madrid: Iberoamericana de Publicaciones, 1930. Edición digital de la Biblioteca Virtual Miguel de Cervantes. Disponível em: http://www.cervantesvirtual.com/obra/martes-de-carnaval-esperpentos-876533/ Acesso em: 6 dez. 2018.

ZOLÁ, Emile: O romance experimental e o naturalismo no teatro. Rio de Janeiro: Elos, 1979 .

i Professor do Programa de Pós-Graduação em Letras da Universidade Federal de Pernambuco.

dajego@hotmail.com 